\title{
Parametric Analysis of a Mechanical Draft Cooling Tower using Two Mathematical Models
}

\author{
Luis Guillermo Obregon-Quiñones ${ }^{1, *}$, Cristian Alexis Aristizábal-González ${ }^{1}$ and Miguel Antonio Caro- \\ Candenazo $^{2}$
}

${ }^{I}$ Research Group on Sustainable Chemical and Biochemical Processes, Chemical Engineering Program, Universidad del Atlántico, Carrera 30 \# 8- 49 Puerto Colombia, Atlantico, Colombia

${ }^{2}$ Department of Mathematics, Universidad del Atlántico, Carrera 30 \# 8-49 Puerto Colombia, Atlantico, Colombia

Received 15 March 2021; Accepted 25 June 2021

\begin{abstract}
In the present work, a Matlab ${ }^{\circledR}$ computer code for cooling tower simulation was developed to perform a parametric analysis that determines the effect of the column cross-sectional area on multiple operating variables such as air humidity, air and water outlet temperature, among others. The computer code uses the Merkel's model and the CDAWC (Continuous Differential Air-Water Contactor) model for later comparison. It was observed a decrease in the outlet water temperature by approximately $14 \%$ when the tower's cross-sectional area increased from 1 to $2 \mathrm{~m} 2$. It increases the air outlet temperature by about $17 \%$ due to increased air-water contact. A negative convective heat transfer in the air was obtained in the cooling tower's bottom due to the large amount of energy required for the heat transfer by vaporization, which was much larger than the convective heat. The evaporative heat transfer is over $80 \%$ of the total heat transferred.
\end{abstract}

Keywords: Cooling tower, Cross-sectional area, Energy, Mass Transfer Coefficient, Mathematical model

\section{Introduction}

Heat transfer is a common transport phenomenon applied in most small and large scale industrial processes. When required to work with specific temperatures of high precision and high purity fluids, the most used equipment to take advantage of this phenomenon are the shell and tube heat exchangers, the plate heat exchangers, and the plate and fin heat exchangers. However, multiple cases are necessary to work on a large scale where direct gas-fluid contact increases heat exchange due to mass and energy transfer. This combined transport phenomenon shows the great importance of cooling towers since they can treat vast amounts of fluid, even water from a whole industrial processing plant such as chemical, petrochemical, thermoelectric plants, etc. The use of cooling towers also applies to large air conditioning units [1-3]. The dimensioning and handling of equipment that involve mass and energy transfer is one of the essential tasks that a chemical engineer performs in his professional performance [4]. Achieving an excellent performance of these columns is a challenge due to the many variables and equations involved.

The use of cooling towers has had a significant increase since 1918. These columns were built using a lot of empirical knowledge because there were not enough design equations that described all the phenomenological parts involved in these equipment's operation. Understanding the fundamental bases of all the phenomena involved to obtain results quickly has promoted the research and development of new robust mathematical models $[5,6]$. The models can be used to make computer simulations that can predict the system's behavior

*E-mail address:_luisobregon@mail.uniatlantico.edu.co ISSN: 1791-2377 @ 2021 School of Science, IHU. All rights reserved. doi:10.25103/jestr.143.05 and make optimizations [7] that help reduce the time to obtain results with high efficiency $[8,9]$.

It takes a long time to make an experimental analysis of a cooling tower's performance because of the high number of variables to consider, such as liquid flow, gas flow, gas inlet temperature, liquid inlet temperature, humidity, tower area, packing types, etc., [10]. On the other hand, there are times when the equipment is not available due to the need for general maintenance. Many expenses are required to obtain the best-operating conditions in a cooling tower, which is not economically feasible for companies. However, the need to understand phenomena in cooling towers makes it necessary to build new columns to do lots of experiments [11] to validate the theoretical models.

The technological development, mainly in the increase of computational power, has allowed the computational simulations to arise as a solution before this problem, making it possible to obtain results quickly and with high accuracy [12]. Besides, the simulations allow modifications to the towers' operating conditions in real-time, thus analyzing the performance and operation of these [13, 14]. With the development of more robust mathematical models, the quality of the simulations' results is improved. The use of the computational tools is promoted, saving time compared to the experimental tests. However, very little work is focused on coding algorithms that integrate the robust mathematical models and allow doing in a didactic way the analysis of the effect of the operating conditions and types of packaging on the output variables $[9,15]$.

It is necessary to develop and implement a simulation code of cooling towers to help solve the exposed problem. It can analyze the operating conditions and other factors that affect these units' performance using realistic mathematical models that obtain a high degree of reliability [16]. 
The gas entering the towers is usually the ambient air. For this reason, these heat transfer equipment are affected by environmental conditions, and their effect contributes to obtaining significant differences in the performance of these cooling systems [17]. Thus, it is essential to determine the optimal operating conditions and the variables that can have the highest effect on the towers' performance $[18,19]$.

The following work presents a Matlab-coded algorithm of two mathematical models to simulate the behavior of cooling towers. The traditional MERKEL model and the CDAWC (Continuous Differential Air-Water Contactor) model were used. Both models, experimentally validated, were used to simulate a cooling tower's behavior under specific operating conditions. It helped to analyze output variables such as the liquid temperature at the tower outlet, heat transfer rate inside the tower height, gas outlet temperature, and humidity as a function of the tower area. It is an essential parameter due to its direct relationship with air-water contact. Understanding the obtained results helps decide about selecting the working area strictly related to the tower packing containing the value of the desired volumetric mass transfer coefficient (kya).

\section{Description of the computational coding.}

A well-structured Graphical User Interface (GUI) was designed to make the Matlab coding of the algorithm to simulate cooling towers easily. The GUI allows the system to be easily visualized and understood while enabling results to be obtained quickly. The organization of the GUI helps you to compare multiple variables of the mathematical models used. The Merkel model and the CDAWC (Continuous Differential Air-Water Contactor) model were coded for simulation of induced draft cooling towers, allowing analysis of operating conditions' effect on cooling tower performances.

The code, along with the GUI, was designed for engineers to perform cooling tower designs and simulations. However, it can also be used by teachers of chemical, mechanical, and process engineering at the graduate level due to the level of complexity. The code could help teachers improve the methodology of theory and practice in advanced mass transfer courses by implementing a virtual laboratory where students can study different operating conditions and configurations of cooling towers quickly. It allows students to develop critical thinking $[20,21]$ and in-depth analysis skills about the phenomena that govern cooling towers' operation [9]. The algorithm lets determine four variables: water flow, tower height, final water temperature, and volumetric mass transfer coefficient. For each of the calculation sequences, several graphs are obtained to analyze the cooling towers, such as the operating line, the equilibrium curve, the air temperature profile, and the air humidity profile.

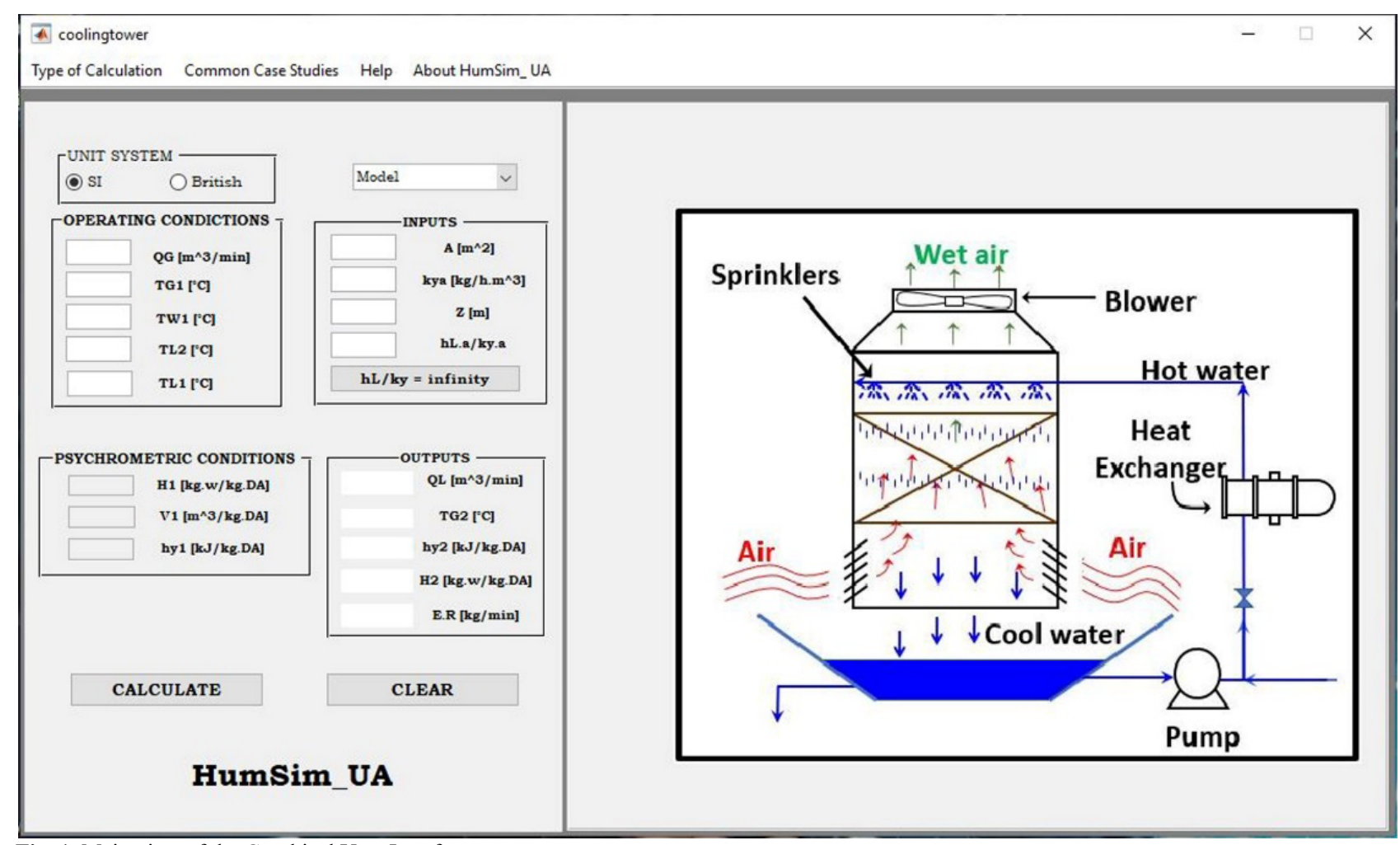

Fig. 1. Main view of the Graphical User Interface.

Fig. 1 shows the main view of the graphical user interface (GUI), highlighting its easy understanding and operation, with the possibility of using the International System of Units or the English system of units.

The coding of the two models used performs iterative processes until finding the correct solution to the studied problem. Fig. 2 shows one of the many algorithms used to perform the calculations.

\section{Equations}

The new code allows the use of two mathematical models, the Merkel model and the CDAWC model. The latter was developed by Llano et al. (2017) [1] at the Universidad del Valle, Colombia. It is a model that consists of 4 differential equations that do not neglect the evaporated water and are used in countercurrent cooling towers.

For the CDAWC model, an infinitesimal section of the tower was used to perform the mass and energy balances. 
Each differential equation is obtained from mass and energy balances in the gas phase and the liquid phase, resulting in the system of equations presented below:

$\frac{d Y_{W}}{d z}=\frac{k_{y} a_{M}\left(Y_{W, I}-Y_{W}\right)}{G_{B}}$

$\frac{d L}{d z}=k_{y} a_{M}\left(Y_{W, I}-Y_{W}\right)$

$\frac{d T_{G}}{d z}=\frac{h_{G} a_{H}\left(T_{L}-T_{G}\right)+k_{y} a_{M}\left(Y_{W, I}-Y_{W}\right) \int_{T_{G}}^{T_{L}} C_{P, W}^{(g)}(T) d T}{G_{B}\left[C_{P, B}\left(T_{G}\right)+Y_{W} C_{P, W}^{(g)}\left(T_{G}\right)\right]}$

$\frac{d T_{L}}{d z}=\frac{h_{G} a_{H}\left(T_{L}-T_{G}\right)+k_{y} a_{M}\left(Y_{W, I}-Y_{W}\right) \Delta H_{v a p, W}\left(T_{L}\right)}{L C_{P, W}^{(L)}\left(T_{L}\right)}$

Eq. (1) refers to the variation of absolute humidity along with the height of the tower, where $Y_{W}$ is the absolute humidity of the air in the gas phase, $Y_{W, I}$ is the absolute humidity of the air at the liquid-gas interface, $k_{y} a_{M}$ is the volumetric mass transfer coefficient and $G_{B}$ is the mass flux of dry air. Eq. (2) refers to the variation of mass flux of water through the tower, where $L$ is the mass flux of water. Eq. (3) refers to the variation of dry bulb temperature of the air through the tower, where $T_{G}$ is the dry bulb temperature of the air, $h_{G} a_{H}$ is the volumetric convective heat transfer coefficient, $T_{L}$ is the liquid water temperature, $C_{P, W}^{(g)}$ is the heat capacity of water vapor and $C_{P, B}$ is the heat capacity of dry air. Finally, Eq. (4) refers to the variation of water temperature through the cooling tower, where $\Delta H_{\text {vap, } W\left(T_{L}\right)}$ is the enthalpy of water vaporization evaluated at liquid phase temperature and $C_{P, W}^{(L)}$ is the heat capacity of water in the liquid phase.

The Merkel model is shown in Eq. (5).

$$
\frac{k_{y} a_{M} Z_{T}}{L}=\int_{T_{L 1}}^{T_{L 2}} \frac{C_{P, W}^{(L)}\left(T_{L}\right) d T_{L}}{\left[H_{G}^{s a t}\left(T_{L}\right)-H_{G}\left(T_{G}, Y_{W}\right)\right]}
$$

It is also necessary to know important properties of the air such as absolute humidity $\left(Y_{W}\right)$, air enthalpy $\left(H_{G}\right)$, dry-bulb temperature $\left(T_{G}\right)$ and wet bulb temperature $\left(T_{W B}\right)$, which are found knowing only two properties.

The wet saturation pressure must be determined with Antoine's equation, see Eq. (6):

$\log \left(P_{T_{W B}}\right)=A-\frac{B}{C+T_{W B}}$

where $P_{T_{W B}}$ is the saturation pressure evaluated at wet air temperature, $\mathrm{A}, \mathrm{B}$, and $\mathrm{C}$ are Antoine's constants for air.

The Eq. (7) shows the saturation humidity:

$Y_{W}^{S a t}=\frac{0.621945 P_{T_{W B}}}{101.325-P_{T_{W B}}}$

where $Y_{W}^{S a t}$ is the absolute humidity of air saturation. The absolute air humidity can be determined using Eq. (8).

$Y_{W}$

$=\frac{\left(\Delta H_{v a p, W}-2326 T_{W}\right) Y_{W}^{S a t}-C_{P, B}\left(T_{G}-T_{W}\right)}{\Delta H_{v a p, W}+C_{P, W}^{(l)} T_{G}-4186 T_{W}}$

The heat capacities can be determined according to the empirical expression shown in Eq.(9).
$C_{P} / R=A+B T+C T^{-2}$

where $\mathrm{R}$ is the universal gas constant, $\mathrm{T}$ is the absolute temperature, and $\mathrm{A}, \mathrm{B}, \mathrm{C}$, and $\mathrm{D}$ are constants.

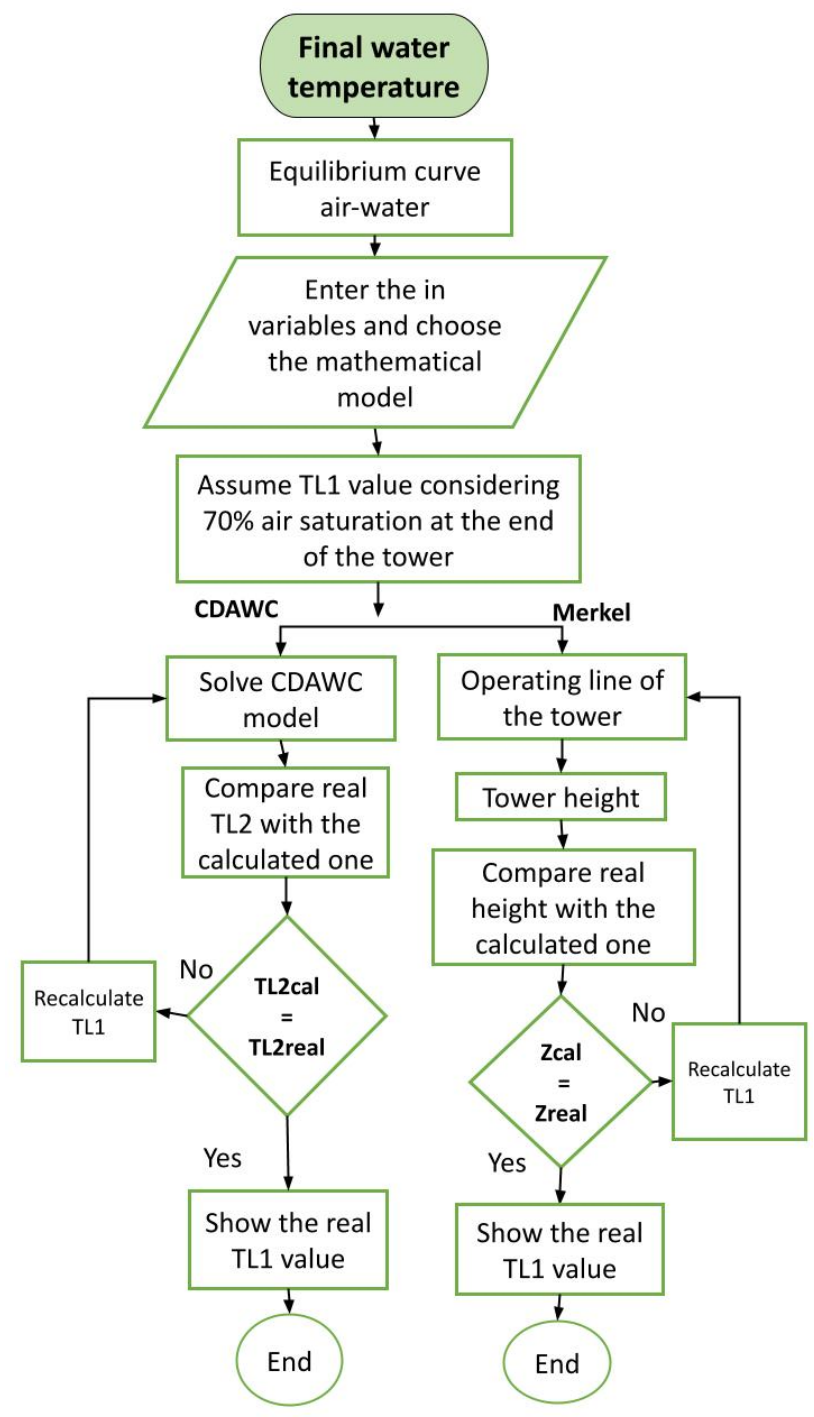

Fig. 2. Algorithm to determine the output temperature of the liquid. Eq. (10).

The specific enthalpy of moist air can be obtained with

$H_{G}=C_{P, B} T_{G} Y_{W}\left(\Delta H_{v a p, W}+C_{P, W}^{(l)} T_{G}\right)$

Finally, the specific volume of wet air can be obtained with Eq. (11).

$V=\left(\frac{1}{P M_{\text {air }}}+\frac{Y_{W}}{P M_{\text {water }}}\right) R T_{G}$

Where $V$ is the specific volume of wet air, $P M_{\text {air }}$ $[\mathrm{kg} / \mathrm{kmol}]$ is the molecular weight of the air, $P M_{\text {water }}$ is the molecular weight of the water, and $R$ is the Universal gas constant.

The efficiency of a cooling tower can be defined as the ratio of the operating range of temperatures to the ideal range., It is determined with Eq. (12), [22]: 
$\% \varepsilon=\frac{T_{L 2}-T_{L 1}}{T_{L 2}-T_{W B 1}}$

The rate of heat transfer by convection is determined using the volumetric heat transfer coefficient and the temperature difference between air and water, as shown in Eq. (13):

$\dot{Q}_{\text {Conv }}=h_{G} a\left(T_{L}-T_{G}\right)$

The heat transfer rate by evaporation is determined using the volumetric mass transfer coefficient with the difference in humidity between the gas phase and the liquid-air interface, as shown in Eq. (14):

$\dot{Q}_{\text {Evap }}=k y a\left(Y_{W, I}-Y_{W}\right) \Delta H_{v a p}\left(T_{L}\right)$

\section{Validation of the mathematical models}

Table 1. Results of regression analysis for the parameter kya for the Merkel and CDAWC models.

\begin{tabular}{c|c|c}
\hline & CDAWC & Merkel \\
\hline $\mathbf{C}_{\mathbf{1}}$ & 244.9461 & 215.1130 \\
$\mathbf{C}_{\mathbf{2}}$ & 0.31407 & 0.29409 \\
$\mathbf{C}_{\mathbf{3}}$ & 0.55411 & 0.63881 \\
$\mathbf{C}_{\mathbf{4}}$ & -1.17900 & -1.27425 \\
$\mathbf{S S E}$ & 7299.47 & 5931.98 \\
$\mathbf{R}^{\mathbf{2}}$ & 0.983 & 0.984 \\
\hline
\end{tabular}

The water outlet temperature is compared with the code using both mathematical models. The remaining $60 \%$ of the experimental data is used to compare the predictions, as shown in Fig. 3.

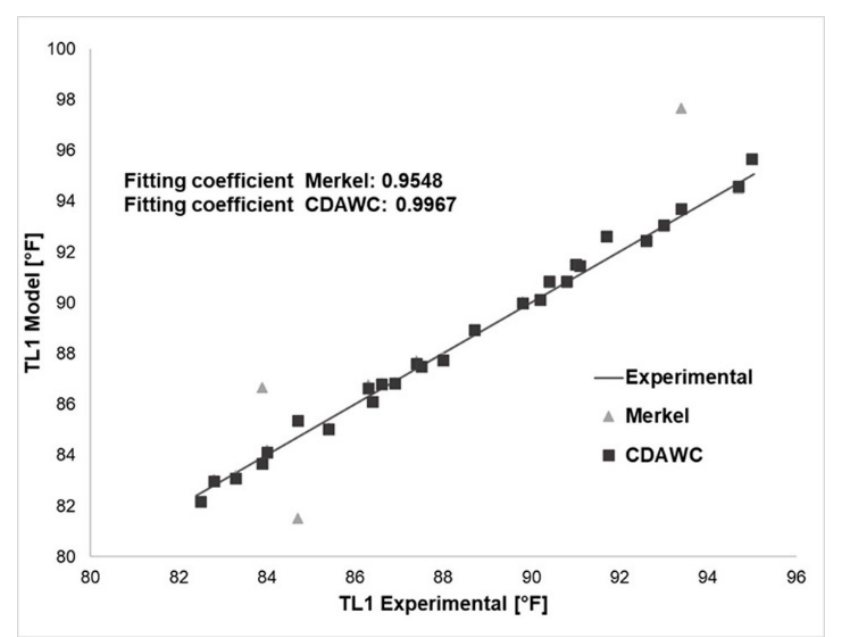

The data reported by Simpson and Sherwood (1946) [3] were used to validate the mathematical models. They did experiments to measure the outlet temperature of water and air for different operating conditions in a laboratory-scale cooling tower. The authors used a 3.45 feet tower and reported 45 experiments to determine the volumetric mass transfer coefficient based on Merkel's model.

The mathematical models CDAWC and MERKEL were used with $40 \%$ of the entire data to find a new correlation of kya (volumetric mass transfer coefficient) as a function of the liquid flux, the gas flux, and the inlet liquid temperature, resulting in Eq. (15).

$$
k_{y} a_{M}=C_{1}(L)^{C_{2}}\left(G_{B}\right)^{C_{3}}\left(T_{L 2}\right)^{C_{4}}
$$

The regression analysis results are reported in Table 1, where the objective was to minimize the sum of squared error (SSE).
Fig. 3. Comparison of prediction models for the outlet liquid temperature As shown in Fig. 3, both models fit quite well to the experimental results; however, the CDAWC model has a coefficient of determination of 0.9967 , while for the Merkel model, it is 0.9548 .

T-student tests were performed with a $95 \%$ confidence level to check if there are significant differences between the experimental measurements' models. For the comparison of the models with the experimental data, the following hypotheses were considered:

$$
\begin{aligned}
& H_{0}: \overline{T L 1}_{\text {Model }}=\overline{T L 1}_{\text {Exp }} \\
& H_{a}: \overline{T L 1}_{\text {Model }} \neq \overline{T L 1}_{\text {Exp }}
\end{aligned}
$$

The null hypothesis (Ho) states that the model's average temperature of the liquid outlet is equal to the experimental measurements' average. In contrast, the alternative hypothesis states that they are different. Therefore, it is a 2-tailed statistical test. Tables 2 and 3 show the statistical test results

\begin{tabular}{|c|c|c|}
\hline & TL1 Merkel & TL1 Exp \\
\hline Mean & 88.863 & 88.578 \\
\hline Variance & 17.519 & 13.805 \\
\hline Count & 23 & 23 \\
\hline Pearson's correlation coefficient & 0.955 & \\
\hline Degrees of freedom & 22 & \\
\hline t-value & 1.071 & \\
\hline P-value (one tail) & 0.148 & \\
\hline t- critical value (one tail) & 1.717 & \\
\hline P-value (two tails) & 0.296 & \\
\hline
\end{tabular}
using the Merkel and CDAWC models, respectively.

Table 2. Statistical test results for the Merkel model with a $95 \%$ confidence level. 
Table 3. Statistical test results for the CDAWC model with a $95 \%$ confidence level

\begin{tabular}{|c|c|c|}
\hline & $T L 1 C D A W C$ & $T L 1 \operatorname{Exp}$ \\
\hline Mean & 88.569 & 88.448 \\
\hline Variance & 14.799 & 13.743 \\
\hline Count & 27 & 27 \\
\hline Pearson's correlation coefficient & 0.997 & \\
\hline Degrees of freedom & 26 & \\
\hline t-value & 1.868 & \\
\hline P-value (one tail) & 0.037 & \\
\hline t- critical value (one tail) & 1.706 & \\
\hline P-value (two tails) & 0.073 & \\
\hline t- critical value (two tails) & 2.056 & \\
\hline
\end{tabular}

Tables 2 and 3 show that the t-value is lower than the tcritical value corresponding to the 2 -tailed test. In both cases, the null hypothesis is accepted. It indicates no significant differences between the CDAWC and Merkel models' results with the experimental measurements' data.

\section{Results and Discussion}

A parametric analysis was performed to see the effect of the most critical variables on the cooling towers' performance to understand better the transport phenomena involved. Different plots are shown to analyze the area's impact on variables such as air temperature, air humidity, water temperature, and heat transfer rates in the tower.

5.1. Effect of the cross-sectional area on the air humidity profile inside the cooling tower

The effect of the tower cross-sectional area on the humidity profile was analyzed for both the Merkel and CDAWC models. The following operating conditions were used, air inlet volumetric flow rate of $150 \mathrm{~m}^{3} / \mathrm{min}$, dry bulb temperature of $22^{\circ} \mathrm{C}$, wet bulb temperature of $15^{\circ} \mathrm{C}$, water inlet volumetric flow rate $0.13 \mathrm{~m}^{3} / \mathrm{min}$, a water inlet temperature of $35^{\circ} \mathrm{C}$, mass transfer volumetric coefficient of $1200 \mathrm{~kg} / \mathrm{h} . \mathrm{m}^{3}$ in a cooling tower with a height of $10 \mathrm{~m}$. The results are shown in Fig. 4.

Fig. 4 shows four curves with the same starting point $(Z=0$ $\mathrm{m})$ because the inlet air conditions are kept constant at that location. It can be seen that as the air rises, its humidity increases due to it has not reached its saturation point allowing the tower to be more efficient in its cooling. This effect is increased when increasing the cross-sectional area of the tower. It happens because as the cross-sectional area increases, the packing area increases, causing an increase in water-air contact. It enhances the mass transfer rate producing more evaporated water resulting in higher air humidity.

It is also observed that the humidity profiles obtained with the Merkel model tend to be similar to a straight line than those obtained with the CDAWC model. It happens because the Merkel model's assumptions do not consider the amount of water evaporated or the variations of water properties as a function of temperature. However, the outlet humidity of the air using both models is very similar. It is necessary to highlight that the air tends to reach its saturation point when the cross-sectional area is increased. Thus, an increase of the area beyond this point would indicate that the heat transfer rate would be obtained only by convection, and the tower would lose efficiency [23]. Fig. 5 shows the different operating lines where the effect of air saturation can be better explained by increasing the area.

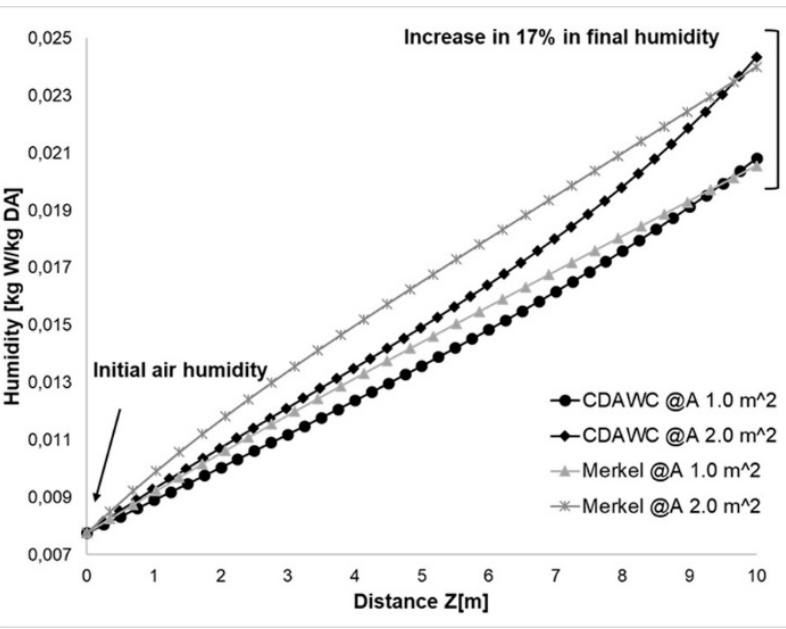

Fig. 4. Moisture profile as a function of tower height for different crosssectional areas using CDAWC and Merkel models.

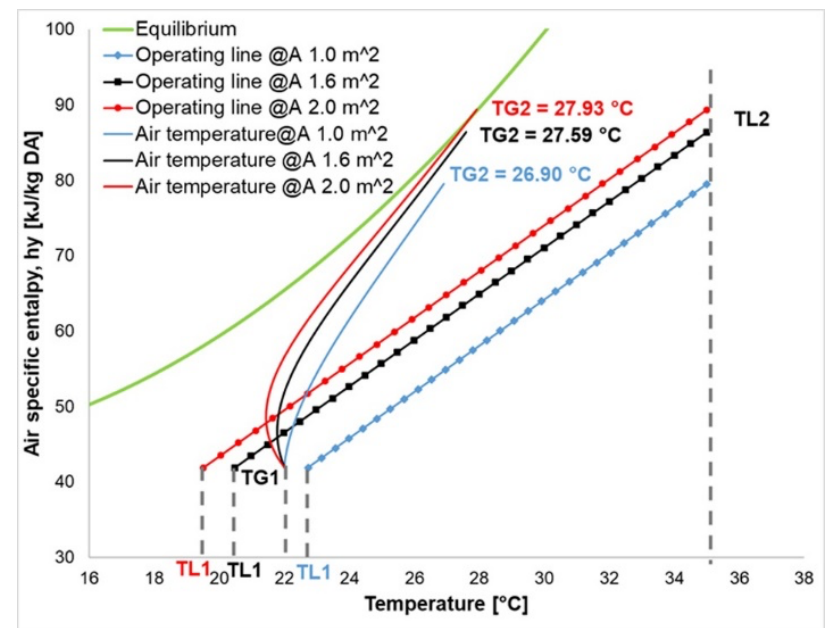

Fig. 5. Effect of the cross-sectional area on the operating line of the cooling tower

Fig. 5 shows that the operating line approaches the equilibrium curve as the cooling tower's cross-sectional area increases. When the tower has an area of $2 \mathrm{~m}^{2}$, the air comes out completely saturated. Thus, the outlet water temperature difference is higher when the area is changed from 1 to $1.6 \mathrm{~m}^{2}$ than when it is changed from 1.6 to $2 \mathrm{~m}^{2}$. When the air tends to approach its saturation point, the heat transfer rate is caused mainly by convection, which is lower than the heat transfer rate by evaporation, causing the behavior observed in Fig. 5 . It happens because the water has a high latent heat of evaporation. 


\subsection{Effect of the cross-sectional area and volumetric} flow rate of the air on the volumetric mass transfer coefficient (kya)

The volumetric mass transfer coefficient was determined using both models with the following operating conditions: dry bulb temperature of $22^{\circ} \mathrm{C}$, wet bulb temperature of $15^{\circ} \mathrm{C}$, a water flow rate of $0.13 \mathrm{~m}^{3} / \mathrm{min}$, a water inlet temperature of $35^{\circ} \mathrm{C}$, the water outlet temperature of $20^{\circ} \mathrm{C}$ in a cooling tower height of $10 \mathrm{~m}$. The air's volumetric flow rate was ranged between $140 \mathrm{~m}^{3} / \mathrm{min}$ and $180 \mathrm{~m}^{3} / \mathrm{min}$. The cross-sectional areas of the tower used were $1 \mathrm{~m}^{2}$ and $2 \mathrm{~m}^{2}$. Fig. 6 shows the behavior using the two models.

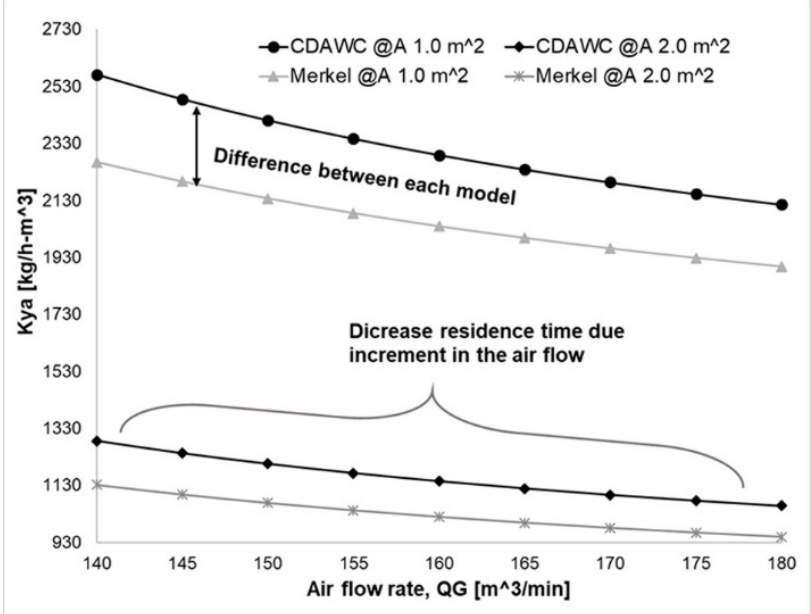

Fig. 6. Volumetric mass transfer coefficient as a function of the volumetric airflow rate and the cross-sectional area of the tower. Models used: CDAWC and Merkel.

Because the inlet and outlet conditions of the water are kept constant in this case study, an increase or decrease in the volumetric mass transfer coefficient (kya) means that different types of tower packing are being used. For the given operating conditions, Fig. 6 shows that it is necessary to use tower packings with a lower volumetric mass transfer coefficient (kya) to increase the tower's cross-sectional area. To better understand this explanation, Eq. (16) was analyzed, which is the Design equation equivalent to Eq. (5):

$$
Z_{T}=\frac{\left(\dot{m}_{L} /_{A}\right) C_{P, W}^{(L)}}{k_{y} a_{M}} \int_{H_{G 1}}^{H_{G 2}} \frac{d T_{L}}{\left[H_{G}^{\text {sat }}-H_{G}\right]}
$$

where $\dot{m}_{L}$ is the liquid mass flow rate, and A is the crosssectional area of the cooling tower. A tower packing with a high mass transfer coefficient (kya) is required to work with a new tower with a smaller cross-sectional area and maintain the same cooling conditions. Eq. (16) shows that the crosssectional area is in the denominator of Eq. (16). It indicates that an increase in the volumetric mass transfer coefficient (kya), keeping the other variables constant, implies a decrease in the cross-sectional area.

On the other hand, Fig. 6 shows that as the volumetric airflow rate increases, the kya value decreases when the water temperature drops from $35^{\circ} \mathrm{C}$ to $20^{\circ} \mathrm{C}$. This behavior can be explained with the help of Fig. 7, which shows different operating lines of the system, maintaining a constant sectional area of $2 \mathrm{~m}^{2}$ using multiple volumetric airflow rates.

Fig. 7 shows that as airflow increases, the operating line moves away from the equilibrium line. It causes an increase in the enthalpy gradient of the gas phase between the interface and the bulk, increasing the heat exchange driving force. It makes the denominator of the integral of Eq. (16) increase; hence the value of the total integral decreases. It causes kya to decrease to keep the height ( $\mathrm{z}$ ) constant. In summary, a reduction in kya is obtained when the airflow is increased. The same behavior was observed experimentally by Obregon et al. (2018), [24].

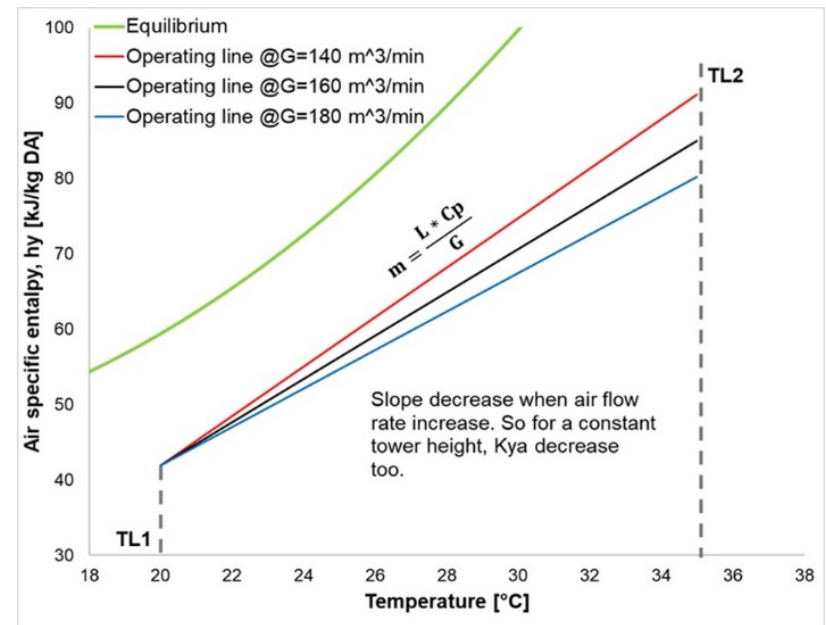

Fig. 7. Effect of the airflow rate on the tower operating line for a fixed area of $2 \mathrm{~m}^{2}$.

When analyzing the two mathematical models' results, it can be seen that Merkel's model obtains lower kya values than the CDAWC model [1]. kya is a parameter that indicates how much water evaporates depending on the air-liquid contact on the surface of the tower packing. Hence, the higher the kya, the better the air-liquid contact in the packing resulting in higher evaporation. Working with the same operating conditions, when using the CDAWC model, the slope of the operating line in Fig. 8 tends to decrease because this model considers the evaporated liquid in both the mass balance and the energy balance. Therefore, LCDAWC $<$ LMERKEL indicates that more evaporated water is obtained with the CDAWC model than with the Merkel model. It can happen while maintaining the same operating conditions and the same tower height by increasing the kya value in the CDAWC model. Therefore, the CDAWC model presents higher kya values than MERKEL's using the same operating conditions.

\subsection{Effect of the area on the water temperature profile}

For the following analysis, cross-sectional areas of $1 \mathrm{~m}^{2}$ and $2 \mathrm{~m}^{2}$ were used with the following operating conditions, inlet air volumetric flow of $150 \mathrm{~m}^{3} / \mathrm{min}$, dry bulb temperature of $22^{\circ} \mathrm{C}$, wet bulb temperature of $15^{\circ} \mathrm{C}$, water inlet flow of 0.13 $\mathrm{m}^{3} / \mathrm{min}$, an inlet water temperature of $35^{\circ} \mathrm{C}$, mass transfer volumetric coefficient of $1200 \mathrm{~kg} / \mathrm{h} \cdot \mathrm{m}^{3}$ and a tower height of $10 \mathrm{~m}$. The results are shown in Fig. 9.

Fig. 9 shows that all the curves converge at the same point $(\mathrm{Z}=10 \mathrm{~m})$. This point is at the top of the tower, where the temperature is the same for all cases $\left(\mathrm{TL}=35^{\circ} \mathrm{C}\right)$. When the water moves down inside the tower, its temperature decreases until reaching the bottom. It can be seen that the larger the cross-sectional area, the lower the outlet temperature of the water. It happens because, for a large cross-sectional area, it is needed a large volume of the tower for the same height. It indicates the use of more tower packing per unit of liquid and airflow rates. 


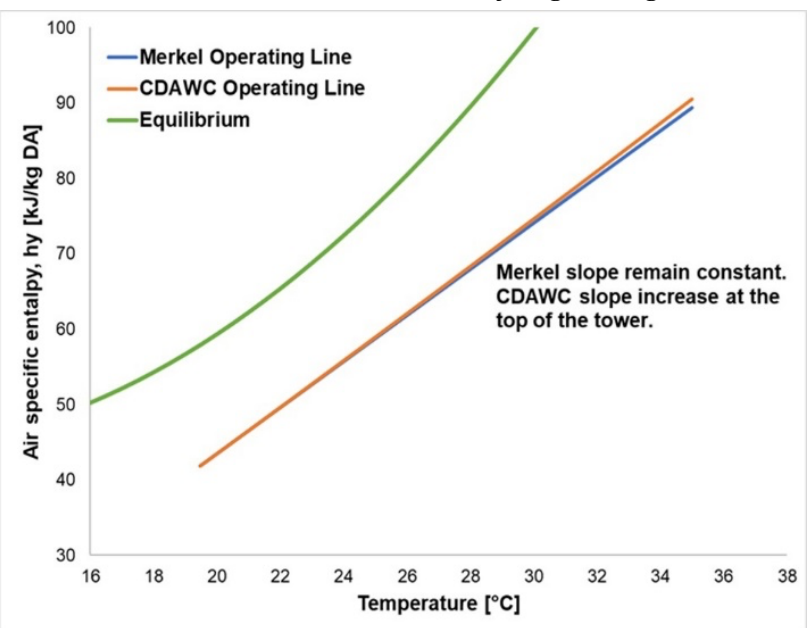

Fig. 8. Behavior of the slope of the operating line using CDAWC and Merkel models.

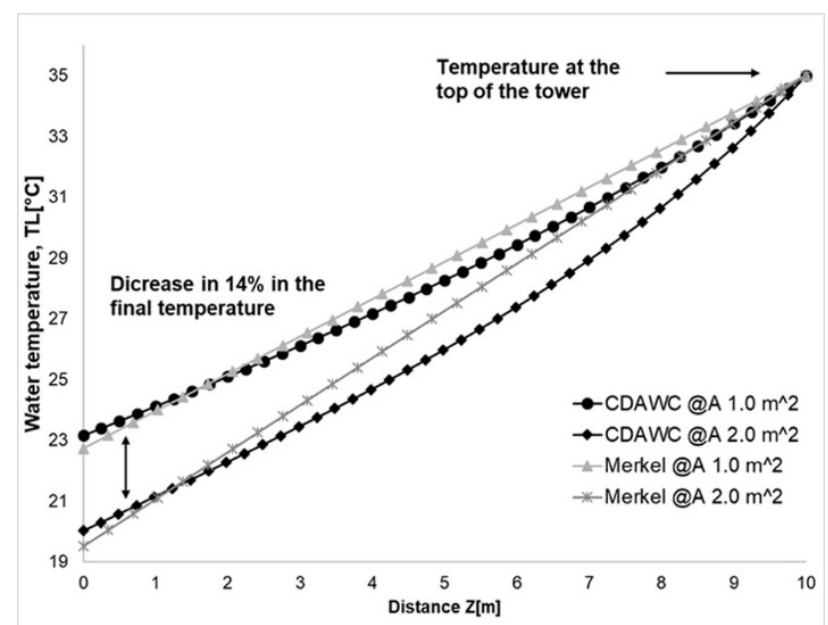

Fig. 9. Water temperature profile for different cross-sectional areas using CDAWC and Merkel models

It means a higher surface area of contact causes a high heat transfer by convection as well as a high evaporation rate, decreasing the liquid's temperature even more [22, 25, 26]. Area variations from 1 to $2 \mathrm{~m}^{2}$ reduce the final water temperature by approximately $14 \%$ and increase the tower efficiency from $61 \%$ to $77 \%$. It shows the importance of determining the best cross-sectional area and choosing the best possible tower packing. This result indicates that the tower should be built with the highest cross-sectional area possible. It would involve a high initial construction expense counterbalanced over time with the tower's increased efficiency. It needs to be considered a limitation that avoids air saturation inside the tower to tap the heat transfer's full potential by vaporization. On the other hand, air saturation can cause high liquid losses due to entrainment. It involves using high surface water particle retainers to cause high gas pressure drops in the system, making it necessary to use more powerful fans that spend more energy.

\subsection{Effect of the area on the air temperature profile}

For the following analysis, the same tower size and operating conditions mentioned in section 5.3 were used. The results are shown in Fig. 10.

Fig. 10 shows that all curves start at $22{ }^{\circ} \mathrm{C}$ at the bottom of the tower, which is the inlet air's dry-bulb temperature. Using an area of $2 \mathrm{~m}^{2}$, the curves obtained with the Merkel and CDAWC models start with a decrease in the air temperature, reaching a minimum. Then, the temperature continues increasing to the top. When working with an area of $1 \mathrm{~m}^{2}$, the air temperature rises all the time.

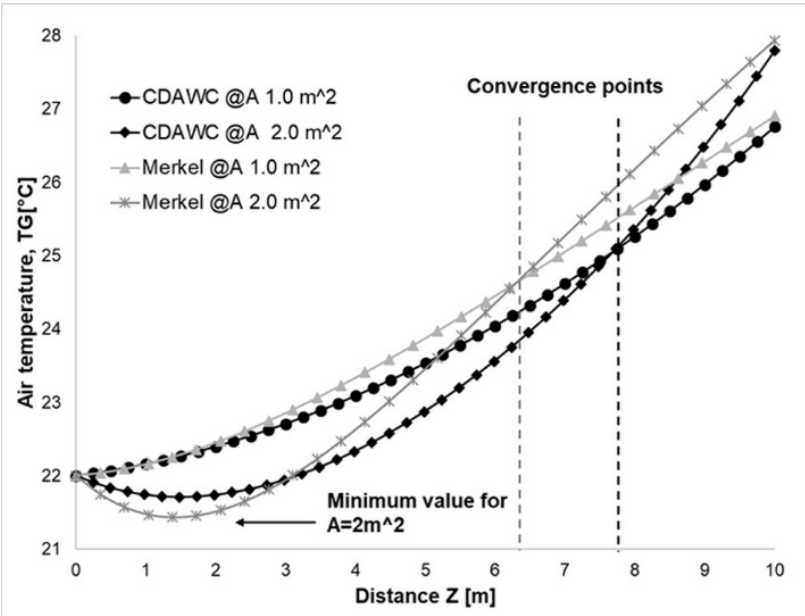

Fig. 10. Air temperature profile as a function of the tower height and cross-sectional area using Merkel and CDAWC models.

A considerable cooling is achieved when working with an area of $2 \mathrm{~m}^{2}$ due to the latent heat of water vaporization. When the water reaches the bottom, it acquires a lower temperature than the air's dry-bulb temperature entering the tower (TG1 > TL1). Hence, heat is transferred by convection from the gas to the water producing a decrease in the air temperature. However, the total heat of vaporization of the water is much larger than the air convective heat resulting in a reduction for both the air and water temperature in a given sector of the tower bottom [25]. Cooling towers aim to remove heat from the water; however, in this case, both air and water decrease their temperature in a sector of the tower bottom. To better understand this phenomenon of a decrease in air temperature in the first meters of packing, Fig. 11 is depicted.

It was decided to work additionally with a cross-sectional area of $3 \mathrm{~m}^{2}$ to observe the air temperature decrease in more detail (see Fig. 11). However, Fig. 11 shows that the air gets saturated faster for this area since the black line reaches the equilibrium curve before reaching the top of the tower. It is a negative effect since water entrainment can occur at the tower's exit, causing electrical equipment problems near the tower. Besides, the water loss would be immense.

In the case of $1 \mathrm{~m}^{2}$, the air temperature always increases and is lower than the water temperature throughout the tower's length. When working with a tower area of $2 \mathrm{~m}^{2}$, Fig. 10 shows negative convection because the air temperature decreases to a minimum around $2 \mathrm{~m}$ of packing height (CDAWC model) and $1.5 \mathrm{~m}$ (Merkel model). Then, the temperature increases as it rises through the tower.

Figs 10 and 11 show that as the cross-sectional area increases, the air leaves the tower at a higher temperature and the water at a lower temperature due to the high air-water contact improving the heat transfer rate [27]. Fig. 10 also shows a point where the curves of $1 \mathrm{~m}^{2}$ and $2 \mathrm{~m}^{2}$ are intercepted. It happens between the heights of $7 \mathrm{~m}$ and $8 \mathrm{~m}$ for the CDAWC model and between $6 \mathrm{~m}$ and $7 \mathrm{~m}$ for the Merkel model. Figs 12 and 13 help in the explanation of this phenomenon by analyzing the heat transfer behavior inside the tower

Fig. 12 shows convection and evaporative heat transfer rates through the tower for the area of $2 \mathrm{~m}^{2}$, using the 


\section{Journal of Engineering Science and Technology Review 14 (3) (2021) 42 - 50}

CDAWC and Merkel models. Heat transfer by evaporation, representing the majority of the total energy transferred with an average of approximately $80 \%$, is maintained almost constant up to about $7 \mathrm{~m}$ in height using the CDAWC model and up to $6 \mathrm{~m}$ using the Merkel model. For heights higher than $7 \mathrm{~m}$ using the CDAWC model and $6 \mathrm{~m}$ with the Merkel model, a high increase in heat transfer rate by evaporation is observed, which means that this is the area where the air temperature increases more significantly.

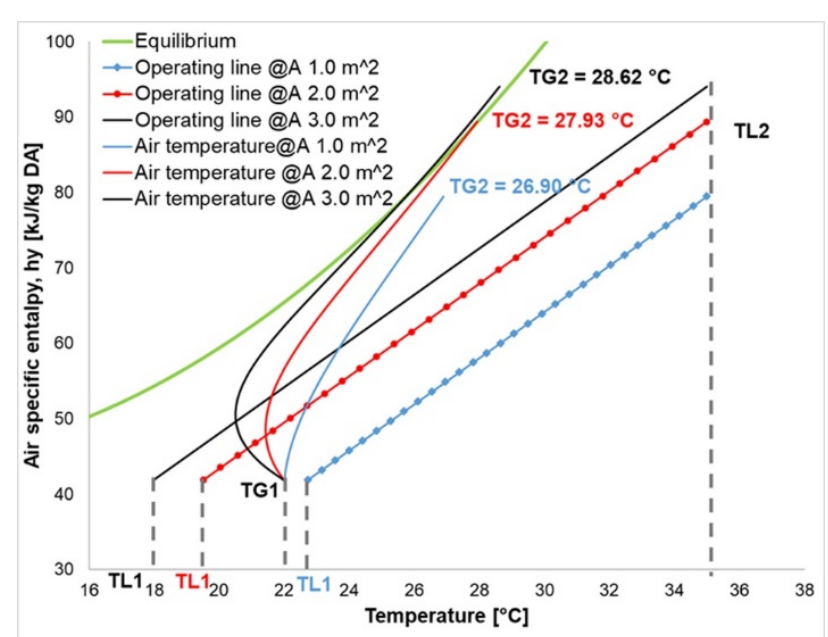

Fig. 11. Comparison of the air and liquid temperature profiles inside the tower using CDAWC and Merkel models for multiple cross-sectional areas.

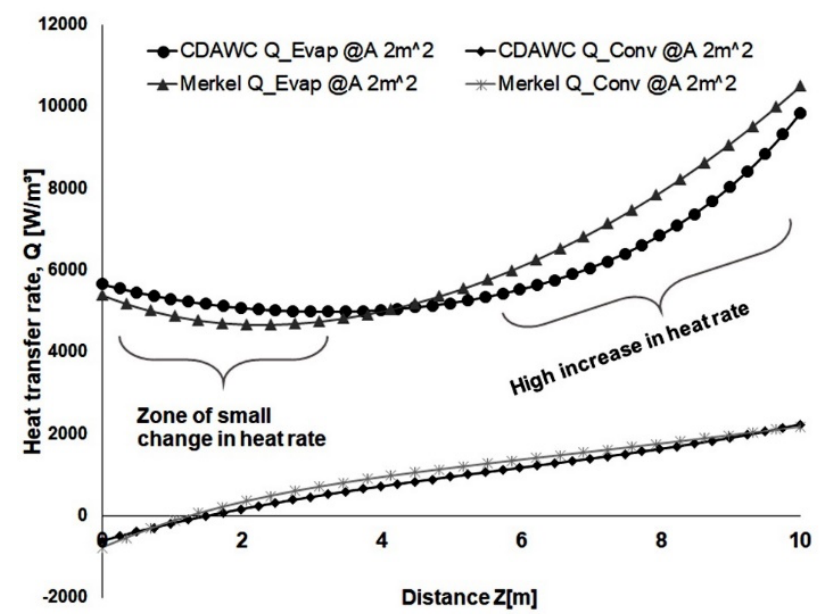

Fig. 12. Heat transfer rates inside the tower for a cross-sectional area of $2 \mathrm{~m}^{2}$. Comparison of CDAWC model and Merkel model.

The same pattern can be seen in Fig. 13, using a crosssectional area of $1 \mathrm{~m}^{2}$. The temperature behaviors observed using both models are similar. The zone of the sudden increase in the total heat of vaporization explains the intersection of the two curves of Fig. 10 when using areas of $1 \mathrm{~m}^{2}$ and $2 \mathrm{~m}^{2}$. In this zone, the total heat transfer rate for an area of $2 \mathrm{~m}^{2}$ is higher than for $1 \mathrm{~m}^{2}$.

Figs. 12 and 13 show that no significant differences are observed between the models for the case of heat transfer by convection. Therefore, the difference obtained in gas and water temperature is due to heat by vaporization.

The small change in the vaporization heat transfer rate in the first few meters of tower packing is observed in Figs. 12 and 13 for the two areas used can be explained in Fig. 14. The evaporation and convection potentials are depicted using the CDAWC and Merkel models.
Fig. 14 shows that the water vaporization potential profile has the same pattern as the vaporization heat shown in Fig. 12. It is logical because the water vaporization is directly proportional to the total heat of vaporization. This potential tends to decrease and increase slightly in the first 6 meters of height and then increase suddenly to the top. Thus, the air temperature has its highest increase in the range from 7 meters to the tower's top.

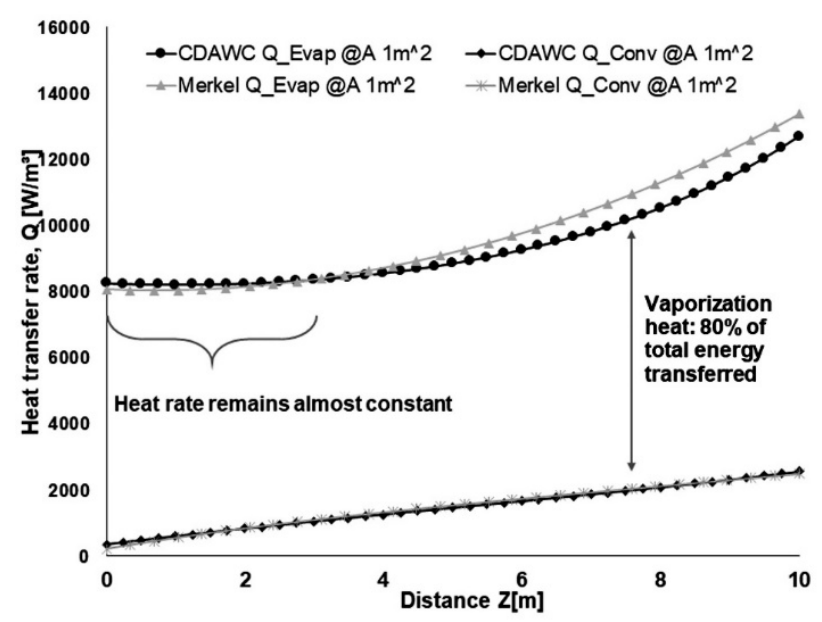

Fig. 13. Heat transfer rates inside the tower for a cross-sectional area of $1 \mathrm{~m}^{2}$. Comparison of CDAWC model and Merkel model.

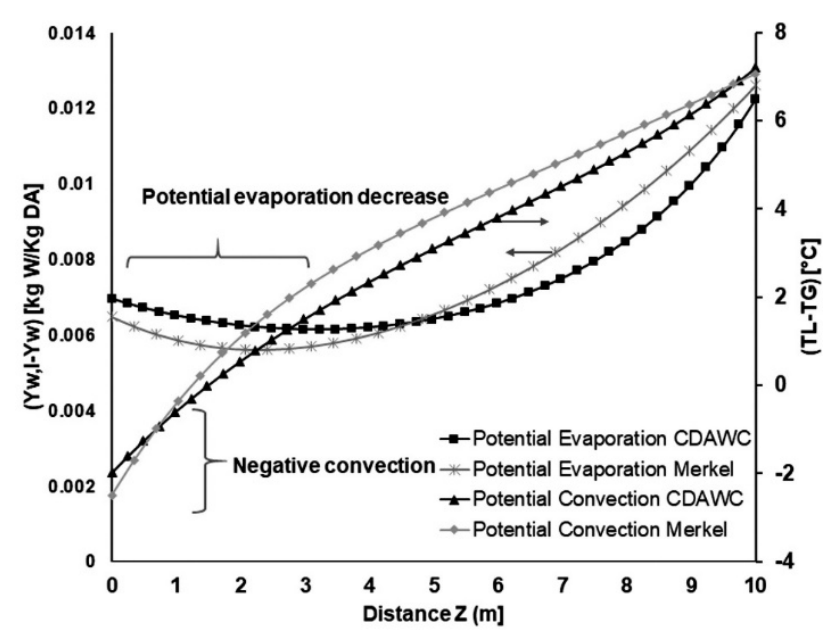

Fig. 14. Vaporization and convection potentials in the cooling tower with a cross-sectional area of $2 \mathrm{~m}^{2}$ using the CDAWC and Merkel models.

It can also be observed that for tower areas of $2 \mathrm{~m}^{2}$, the convective heat transfer from the air to water occurs in the 2 $\mathrm{m}$ of packing from the bottom. Then, the direction is changed, and the heat transfer by convection occurs from the water to the air, which explains the minimum air temperature in the height range from 0 to $2 \mathrm{~m}$ (see Fig. 10).

All these studied behaviors need to be done before making a cooling tower design to make the best possible economic and efficient decision.

\section{Conclusions}

A computer code was developed in Matlab to simulate cooling towers using two mathematical models, CDAWC and Merkel. It was analyzed the effect of the cross-sectional area in the performance of the cooling towers considering multiple 
operation variables, demonstrating its great importance at the time of making tower designs.

When the cross-sectional area increases, the air-water contact is improved, which implies a higher mass transfer that results in a higher cooling of water. Increasing the area from $1 \mathrm{~m}^{2}$ to $2 \mathrm{~m}^{2}$ reduces the water temperature by approximately $14 \%$.

It was shown that a smaller cross-sectional area could be used with a high-efficiency tower packing when cooling requirements remain constant. However, it is necessary to evaluate the costs of packing materials regarding the cooling tower dimensions.

The heat transfer phenomenon by vaporization is higher than the heat transfer by convection by approximately $80 \%$, considering a small control volume in the tower. It happened because water has a high enthalpy of vaporization. This effect is higher for areas larger than $2 \mathrm{~m}^{2}$, where the mass transfer rate is so effective that a negative heat transfer by convection in the air occurs. In this case, the vaporization heat transfer ratio causes both the air and water to lower their temperature. It occurs between the first and second meters of the tower. The evaporative heat transfer rate remains constant, while the convection rate increases until it exceeds the negative convection stage.

\section{Acknowledgment}

The authors want to thank the Universidad del Atlántico for the financial support given with the project research identified with ID ING19-FGI2016, (Fortalecimiento de la capacidad científica del grupo PROQUIBIOS en sus líneas de investigación).

This is an Open Access article distributed under the terms of the Creative Commons Attribution License.

\section{References}

1. M. Llano-Restrepo and R. Monsalve-Reyes, "Modeling and simulation of counterflow wet-cooling towers and the accurate calculation and correlation of mass transfer coefficients for thermal performance prediction," International Journal of Refrigeration, vol. 74, pp. 47-72, 2017.

2. R. F. F. Pontes, W. M. Yamauchi, and E. K. G. Silva, "Analysis of the effect of seasonal climate changes on cooling tower efficiency, and strategies for reducing cooling tower power consumption," Applied Thermal Engineering, vol. 161, pp. 114148, 2019.

3. W. M. S. a. T. K. Sherwood, "Performance of small mechanical draft cooling towers," Am Soc Refrig Eng vol. 52, p. 9, 1946.

4. H. J. Feise and E. Schaer, "Mastering digitized chemical engineering," Education for Chemical Engineers, vol. 34, pp. 78-86, 2021.

5. M. Arif, M. N. khan, and M. Parvez, "Universal Engineering Model for Cooling Towers," International Journal of Engineering Research and Applications, vol. 5, pp. 2248-9622, 2015.

6. H. Ma, F. Si, K. Zhu, and J. Wang, "Quantitative research of spray cooling effects on thermo-flow performance of the large-scale dry cooling tower with an integrated numerical model," International Journal of Heat and Mass Transfer, vol. 141, pp. 799-817, 2019.

7. Y. Zhang, H. Zhang, Y. Wang, S. You, and W. Zheng, "Optimal configuration and operating condition of counter flow cooling towers using particle swarm optimization algorithm," Applied Thermal Engineering, vol. 151, pp. 318-327, 2019.

8. O. M. Hernández-Calderón, E. Rubio-Castro, and E. Y. Rios-Iribe, "Solving the heat and mass transfer equations for an evaporative cooling tower through an orthogonal collocation method," Computers \& Chemical Engineering, vol. 71, pp. 24-38, 2014.

9. L. F. Arrieta, L. G. Obregon, and G. E. Valencia, "A Matlab-Based Program for the Design And Simulation of Wet Cooling Towers," Chemical Engineering Transactions, vol. 57, pp. 1585-1590, 2017.

10. J. C. Kloppers and D. G. Kroger, "Loss coefficient correlation for wet-cooling tower fills," Applied Thermal Engineering, vol. 23, pp. 2201-2211, 2003.

11. G. Zengin and A. Onat, "Experimental and theoretical analysis of mechanical draft counterflow wet cooling towers," Science and Technology for the Built Environment, vol. 27, pp. 14-27, 2021.

12. J. A. Queiroz, V. M. S. Rodrigues, H. A. Matos, and F. G. Martins, "Modeling of existing cooling towers in ASPEN PLUS using an equilibrium stage method," Energy Conversion and Management, vol. 64, pp. 473-481, 2012.

13. N. Blain, A. Belaud, and M. Miolane, "Development and validation of a CFD model for numerical simulation of a large natural draft wet cooling tower," Applied Thermal Engineering, vol. 105, pp. 953-960, 2016.

14. Y. Dementiev, L. Burulko, and E. Suvorkova, "Pedagogical Aspects of Applied Software Packages and Computer Technologies Use in Student's Education," Procedia - Social and Behavioral Sciences, vol. 206, pp. 289-294, 2015.

15. J. C. Kloppers and D. G. Kroger, "Cooling Tower Performance Evaluation: Merkel, Poppe, and e-NTU Methods of Analysis,"
Journal of Engineering for Gas Turbines and Power, vol. 127, pp. 17, 2005.

16. X. Meng, W. Hu, J. Zhou, Y. Cao, Y. Gao, and L. Zhang, "Parametric analysis on the temperature response rules in inner surfaces for the homogeneity walls," Case Studies in Thermal Engineering, vol. 13, p. 100353, 2019.

17. A. Laknizi, M. Mahdaoui, A. Ben Abdellah, K. Anoune, M. Bakhouya, and H. Ezbakhe, "Performance analysis and optimal parameters of a direct evaporative pad cooling system under the climate conditions of Morocco," Case Studies in Thermal Engineering, vol. 13, p. 100362, 2019.

18. Y. Al Horr, B. Tashtoush, N. Chilengwe, and M. Musthafa, "Operational mode optimization of indirect evaporative cooling in hot climates," Case Studies in Thermal Engineering, vol. 18, p. $100574,2020$.

19. N. M. Phu and N. V. Hap, "Influence of inlet water temperature on heat transfer and pressure drop of dehumidifying air coil using analytical and experimental methods," Case Studies in Thermal Engineering, vol. 18, p. 100581, 2020.

20. J. G. Acevedo, G. Valencia Ochoa, and L. G. Obregon, "Development of a new educational package based on e-learning to study engineering thermodynamics process: combustion, energy and entropy analysis," Heliyon, vol. 6, p. e04269, 2020.

21. M. R. D. Biasi, G. E. Valencia, and L. G. Obregon, "A New Educational Thermodynamic Software to Promote Critical Thinking in Youth Engineering Students," Sustainability, vol. 12, p. 110, 2020.

22. L. G. Obregon, J. C. Pertuz, and R. A. Dominguez, "Performance analysis of a laboratory scale cooling tower for different packing materials, water inlet temperature and mass flow ratio water-air," Revista Prospectiva, vol. 15, pp. 42-52, 2017.

23. M. Lemouari, M. Boumaza, and A. Kaabi, "Experimental analysis of heat and mass transfer phenomena in a direct contact evaporative cooling tower," Energy Conversion and Management, vol. 50, pp. 1610-1617, 2009.

24. L. G. Obregon, J. E. Duarte, and G. E. Valencia, "Effect of the area on the behavior of a mechanical draft wet cooling tower," Contemporary Engineering Sciences, vol. 11, pp. 2923-2929, 2018.

25. J.-U.-R. Khan, M. Yaqub, and S. M. Zubair, "Performance characteristics of counter flow wet cooling towers," Energy Conversion and Management, vol. 44, pp. 2073-2091, 2003.

26. J. C. Kloppers, "A critical evaluation and refinement of the performance prediction of wet-cooling towers," Doctoral Thesis, University of Stellenbosch, 2003.

27. A. A. Dreyer, "Analysis of evaporative coolers and condensers," Master of Engineering, Department of Mechanical Engineering, University of Stellenbosch, 1988. 